\title{
Proceeding
}

Supplementary Issue: Summer Conferences of Sports Science. Costa Blanca Sports Science Events, 20-21 September 2019. Alicante, Spain.

\section{Circadian rhythms, physical activity and longevity}

\author{
ROSARITA NASSO, VALENTINA PAGLIARA, ANTONIO ASCIONE, MARIOROSARIO MASULLO, \\ ROSARIA ARCONE \\ Department of Sport and Well-being Sciences, Parthenope University, Naples, Italy
}

\begin{abstract}
Human health implies complex mechanisms and involves diseases prevention aimed at ensuring a psychophysical wellbeing homoeostasis. The search for longevity can be related to the slowdown in aging, and psycho-physical wellbeing is often related to the lifestyle, mainly to the human physical activity and nutrition. Circadian rhythms are processes that affect the behaviour, physiology and metabolism of mammals across cyclic periods of 24 hours. These rhythms are regulated by multiple physiological systems, whose key elements are the alternation between light and dark and between food consumption and periods of fasting. Therefore, during evolution, a constant adaptation to natural rhythms by humans has been established towards the surrounding environment determining periods of food consumption and periods of fasting coinciding with rest. Recent sociological surveys have shown that there is a slight increase in the number of people who devote themselves to a constant physical/sport activity, but this is an ephemeral percentage compared to the dramatic increase in the incidence of diseases related to aging such as obesity and diabetes, easily preventable with healthy lifestyles. Therefore, the connection between circadian rhythms, physical activity and lifestyles represents an important feature involved in human longevity. Here, a survive of the biological mechanisms, implied in this behaviour, is presented. Keywords: Circadian rhythms; Human health; Physical activity; Longevity; Training activity.
\end{abstract}

\section{Cite this article as:}

Nasso, R., Pagliara, V. Ascione, A., Masullo, M., \& Arcone, R. (2019). Circadian rhythms, physical activity and longevity. Journal of Human Sport and Exercise, 14(5proc), S1925-S1930. doi:https://doi.org/10.14198//hse.2019.14.Proc5.11

Corresponding author. Department of Sport and Well-being Sciences, Parthenope University, Naples, Italy.

E-mail: rosaria.arcone@uniparthenope.it

Supplementary Issue: Summer Conferences of Sports Science. Costa Blanca Sports Science Events, 20-21 September 2019. Alicante, Spain.

JOURNAL OF HUMAN SPORT \& EXERCISE ISSN 1988-5202

(c) Faculty of Education. University of Alicante

doi:10.14198/jhse.2019.14.Proc5.11 


\section{INTRODUCTION}

Human health care is a complex mechanism based mainly on prevention to ensure constant psycho-physical wellbeing. This behaviour is especially evident in the extreme oriental population, and it is not surprising that the highest average lifespan is observed in Japan (Yokoyama et al., 2019).

The search for longevity can be related to the slowdown in aging, and psycho-physical wellbeing is often related to the lifestyle, mainly to the human physical activity (Liguori et al., 2019; Montesano and Mazzeo, 2019).

Circadian rhythms are cyclic mechanisms that affect the behaviour, physiology and metabolism of mammals across 24 hours (Hood and Amir, 2017; Sollars and Pickard, 2015). These rhythms are regulated by multiple physiological systems known as "circadian clocks" (Rosbash, 1995), whose key elements are the alternation between light and dark and between food consumption and periods of fasting (Oike, 2017). Therefore, during evolution, a constant adaptation to natural rhythms by humans has been established towards the surrounding environment determining periods of food consumption and periods of fasting coinciding with rest.

Recent sociological surveys have shown that there is a slight increase in the number of people who devote themselves to a physical activity (Saint Onge and Krueger, 2017), but this is an ephemeral percentage compared to the dramatic increase in the incidence of diseases related to aging such as obesity and diabetes, easily preventable with healthy lifestyles (Wyatt et al., 2006; Spann and Ottinger, 2018).

\section{FUNCTIONAL ANATOMY AND MOLECULAR ORGANIZATION OF CIRCADIAN RHYTHMS}

Phylogenetically higher animals have evolved an internal biological clock regulating important physiological pathways, at macroscopic (sleep/wake rhythm, body temperature, etc.), microscopic (blood pressure, metabolic activity, etc) and/or molecular (cell regeneration, hormone secretion, etc.) levels (Froy, 2017). This circadian oscillator, is controlled through the activity of the suprachiasmatic nuclei (SCN) of the brain hypothalamus (Gillette and Tischkau, 1999), which receives the ambient light/dark cycle, and transmit these information to the peripheral circadian clock sensitive organs, mainly liver, heart, gut and lungs, through direct (neuronal) or mediated (humoral) factors (Panda et al., 2002; Schibler et al., 2003). Although each cell of the organism possesses its own circadian rhythm, a synergistic integration among them is required to guarantee organism life. At a molecular level, this finding is attained through a cycle of transcription/translation of some gene products, leading to the modulation of such an integrated mechanism.

The most studied proteins involved in the mammalian circadian cycle are the following (Ko and Takahashi, 2006 and references therein). CLOCK (Circadian Locomotor Output Cycles Kaput) BMAL1 (Brain Muscle ARNT Like1) heterodimeric complex represents a positive transcription modulator of the rhythmic biological processes. CRY (Cryptochromes), PER (Periods), NPAS2, REV, ROR and CK1 gene products, represent negative modulators inhibiting the CLOCK:BMAL1 complex formation. In addition, the autoregulatory feedback loops generated by these proteins is finely modulated by their phosphorylation and/or ubiquitination post-translational modifications levels.

\section{EFFECT OF CIRCADIAN RHYTHMS ON METABOLISM}

Among the peripheral tissue cells affected by circadian clock, the liver cells represent the main target of the metabolism regulation as it plays a central role in catabolic and anabolic process of almost all the 
biomolecules (Panda, 2016). This is achieved by mediating the expression and/or activity of certain metabolic enzymes and transport systems involved in cholesterol metabolism, amino acid regulation, the citric acid cycle and glycogen and glucose metabolism. Furthermore, the intermediates produced in nutrient metabolism lead to the formation of several small molecules that, in turn, can affect clock functions. For instance, some products of ornithine catabolism, affect the polyamine biosynthesis metabolism, a pathway regulated by the circadian clocks at a transcriptional level (Panda et al., 2002, Zwighaft et al. 2015). In addition, in rats, lesions in the SCN, induced an impairment in the homeostasis of circulating glucose (Panda, 2016). Recent studies on genetically modified mice have shown that glucose absorption and ATP concentration in the cellular metabolism of the brain and peripheral tissues are linked to circadian rhythms, as are some hormones, including insulin, glucagon and corticosterone (Stevens et al., 2019).

\section{CIRCADIAN RHYTHMS AND AGEING}

Quality and duration of life are closely related to circadian rhythms (Liu and Chang, 2017). The breakdown of circadian rhythms in relation to the environment leads to the appearance of symptoms such as fatigue, disorientation and insomnia. For instance, shift workers, whose circadian rhythms are compromised, experience serious metabolic alterations, hormonal (Sellami et al., 2019) and sleep disorders. In some studies, CLOCK protein deficiency leads to a drastically reduced life span (Davis and Mirick, 2006; Qureshi and Mehler, 2014). In particular, this deficiency induces the appearance of cataracts, dermatitis and loss of organ tissue, elements that can be attributed to premature ageing.

\section{CIRCADIAN RHYTHMS AND PHYSICAL ACTIVITY}

The relation between the circadian rhythms and physical activity can be associated to hormones level variation during both the physical practice and the circadian rhythms (Sellami el al, 2019). In particular, glucoregulatory hormones, playing a significant role in the human physiology, can be considered targets of the relationship existing between physical activity and circadian rhythms. In addition, being this class of hormones involved in the nutrition-fasting cycle of the life, the synchronization of their levels within the circadian rhythms has been recently proposed (Heden and Kanaley, 2019). Another physiological connection between physical exercise and circadian cellular clocks, has been proposed (Harrington, 2012). In these studies, it has been found that physical exercises carried out in the early of the active phase of the circadian cycle decreased the electrophysiological activity of the suprachiasmatic nuclei with a concomitant increase in the activity of the adrenal gland. On the contrary, exercises scheduled in the second half of the active period, significantly increase the activity of the suprachiasmatic nuclei. Therefore, the question arises if scheduled exercises could improve the physiology of the circadian rhythms.

\section{DISEQUILIBRIUM OF CIRCADIAN RHYTHMS AND DISEASES}

A link between circadian rhythms and physiological disorders has received particular attention by researchers (Bollinger and Schibler, 2014). In particular, among human diseases, the disequilibrium in the circadian clock and incidence of cancer, has been recently reviewed (Masri and Sassone-Corsi, 2018). The main effect of the unbalanced circadian rhythms can be related to the circadian control of cancer metabolism and, in particular, the involvement of the inducible oncogenes c-Myc and Kras and/or the tumour suppressor p53 (Jackson et al., 2001; de Laurentiis et al., 2011; Adornetto et al., 2013; Papagiannakopoulos et al., 2016), oxidative stress (Hanahan \& Weinberg, 2011) as well as tumour microenvironment modification (Masri and Sassone-Corsi, 2018), have been proposed. More recently, the induction of metalloproteinase 9 expression, 
an extracellular protein involved in the cancer progression and invasiveness (Pagliara et al., 2014) has been related to BMAL1 expression, during the circadian rhythms of microbiota (Wu et al., 2019).

\section{CIRCADIAN RHYTHMS PHYSICAL ACTIVITY AND AGEING}

It has been reported that exercise can affect the phase shift of the circadian rhythms in young adults if performed at the right time of day (Baehr et al., 2003). In particular, they found a faster adaptation to a new sleep/dark cycle, upon a physical exercise in the daylight phase of the circadian cycle, whereas physical activity carried out at night accelerated the daytime phase of the circadian clock. Other studies (Youngstedt et al., 2002) indicated that night exercise affects the circadian rhythms of melatonin production in healthy older adults, thus indicating that these effects are not restricted to young people. Thus, it can be argued that the physical activity of older adults might be useful for retarding the physiology of the circadian rhythms if a synchrony with the living environment has to be ensured.

\section{CONCLUSIONS}

In conclusions, the key role between circadian rhythms and human health has already been demonstrated. More recently, this correlation has been associated to human longevity as circadian rhythms can be linked to both physiological and/or pathological conditions in humans. Being the human physical activity a procedure that maintains and ameliorates the body health, its involvement in the circadian rhythms has also been proposed. Therefore, it cannot be excluded that the human training activity can be affected and/or directed by circadian rhythms.

\section{AUTHORS' CONTRIBUTIONS}

The manuscript has been conceived by all the authors, and the specific contribution of which is to be referred to as follows: paragraphs n. 1 and n. 2 are attributed to Rosarita Nasso and Valentina Pagliara, paragraph n. 3 to Antonio Ascione, paragraphs n. 4 and 5 to Mariorosario Masullo and Rosaria Arcone. All the Authors participated to the Introduction and Conclusions paragraphs. Mariorosario Masullo and Rosaria Arcone wrote the manuscript.

\section{REFERENCES}

Adornetto A, Pagliara V, Renzo GD, Arcone R. (2013) Polychlorinated biphenyls impair dibutyryl cAMPinduced astrocytic differentiation in rat C6 glial cell line. FEBS Open Bio 3, 459-466. https://doi.org/10.1016/j.fob.2013.10.008

Baehr EK, Eastman Cl, Revelle W, Olson SH, Wolfe LF, Zee PC. (2003) Circadian phase-shifting effects of nocturnal exercise in older compared with young adults. Am. J. Physiol. Regul. Integr. Comp. Physiol. 284, 1542-1550. https://doi.org/10.1152/ajpregu.00761.2002

Bollinger T, Schibler U. (2014) Circadian rhythms - from genes to physiology and disease. Swiss Med. Wkly 144, w13984. https://doi.org/10.4414/smw.2014.13984

Davis S, Mirick DK. (2006) Circadian disruption, shift work and the risk of cancer: a summary of the evidence and studies in Seattle. Cancer Causes Control 17, 539-545. https://doi.org/10.1007/s10552-005-9010-9

de Laurentiis A, Gaspari M, Palmieri C, Falcone C, laccino E, Fiume G, Massa O, Masullo M, Tuccillo FM, Roveda L, Prati U, Fierro O, Cozzolino I, Troncone G, Tassone P, Scala G, Quinto I. (2011) 
Mass spectrometry-based identification of the tumor antigen UN1 as the transmembrane CD43 sialoglycoprotein. Mol. Cell. Proteom. 10, M111.007898. https://doi.org/10.1074/mcp.m111.007898

Froy O. (2018) Circadian rhythms, nutrition and implications for longevity in urban environments. Proc. Nutr. Soc. 77, 216-222. https://doi.org/10.1017/s0029665117003962

Gillette MU, Tischkau SA. (1999) Suprachiasmatic nucleus: the brain's circadian clock. Recent Prog. Horm. Res. 54, 33-58.

Hanahan D. and Weinberg, RA. (2011) Hallmarks of cancer: the next generation. Cell 144, 646-674. https://doi.org/10.1016/j.cell.2011.02.013

Harrington ME. (2012) Exercise strengthens circadian cloks. J. Physiol. 590, 5929-5929. https://doi.org/10.1113/jphysiol.2012.245308

Heden TD, Kanaley JA. (2019) Syncing Exercise With Meals and Circadian Clocks. Exerc. Sport Sci. Rev. 47, 22-28. https://doi.org/10.1249/jes.0000000000000172

Hood S, Amir S. (2017) The aging clock: circadian rhythms and later life. J. Clin. Invest. 127, 437-446. https://doi.org/10.1172/jici90328

Jackson EL, Willis N, Mercer K, Bronson RT, Crowley D, Montoya R, Jacks T, Tuveson DA. (2001) Analysis of lung tumor initiation and progression using conditional expression of oncogenic K-ras. Genes Dev. 15, 3243-3248. https://doi.org/10.1101/gad.943001

Ko CH, Takahashi JS. (2006) Molecular components of the mammalian circadian clock. Hum. Mol. Genet. 15, R271-R277. https://doi.org/10.1093/hmg/ddl207

Liguori G, Gallé F, Valeriani F, Romano Spica V. (2015) The role of the hygienist in prevention and health promotion through physical activity: the contribute of the Working Group "Movement Sciences for Health" of the Italian Society of Hygiene, Ann. Ig. 27, 11-15.

Liu F, Chang HC. (2017) Physiological links of circadian clock and biological clock of aging. Protein Cell. 8, 477-488. https://doi.org/10.1007/s13238-016-0366-2

Masri S, Sassone-Corsi P. (2018) The emerging link between cancer, metabolism, and circadian rhythms. Nat. Med. 24, 1795-1803. https://doi.org/10.1038/s41591-018-0271-8

Montesano P, Mazzeo F. (2019) Sports Activities in Obese Teenagers Improve Social Inclusion and Health. Sport Mont., 17, 55-60. https://doi.org/10.26773/smj.190210

Oike H. (2017) Modulation of circadian clocks by nutrients and food factors. Biosci. Biotechnol. Biochem. $81,863-870$.

Pagliara V, Adornetto A, Mammì M, Masullo M, Sarnataro D, Pietropaolo C, Arcone R. (2014) Protease Nexin-1 affects the migration and invasion of $\mathrm{C} 6$ glioma cells through the regulation of urokinase Plasminogen Activator and Matrix Metalloproteinase-9/2. Biochim. Biophys. Acta 1843, 2631-2644. https://doi.org/10.1016/..bbamcr.2014.07.008

Panda S, Antoch MP, Miller BH, Su Al, Schook AB, Straume M, Schultz PG, Kay SA, Takahashi JS, Hogenesch JB. (2002) Coordinated transcription of key pathways in the mouse by the circadian clock. Cell 109, 307-20. https://doi.org/10.1016/s0092-8674(02)00722-5

Panda S. (2016) Circadian physiology of metabolism. Science 354, 1008-1015.

Papagiannakopoulos T, Bauer MR, Davidson SM, Heimann M, Subbaraj L, Bhutkar A, Bartlebaugh J, Vander Heiden MG, Jacks T. (2016) Circadian rhythm disruption promotes lung tumorigenesis. Cell. Metab. 24, 324-331. https://doi.org/10.1016/i.cmet.2016.07.001

Qureshi IA, Mehler MF. (2014) Epigenetics of sleep and chronobiology. Curr. Neurol. Neurosci. Rep. 14, 432. https://doi.org/10.1007/s11910-013-0432-6

Rosbash M. (1995) Molecular control of circadian rhythms. Curr. Opin. Genet. Dev. 5, 662-668.

Saint Onge JM, Krueger PM. (2017) Health Lifestyle Behaviors among U.S. Adults. SSM Popul. Health. 3, 89-98. https://doi.org/10.1016/j.ssmph.2016.12.009 
Schibler U, Ripperger J, Brown SA. (2003) Peripheral circadian oscillators in mammals: time and food. J. Biol. Rhythms 18, 250-260. https://doi.org/10.1177/0748730403018003007

Sellami M, Bragazzi NL, Slimani M, Hayes L, Jabbour G, De Giorgio A, Dugué B. (2019) The Effect of Exercise on Glucoregulatory Hormones: A Countermeasure to Human Aging: Insights from a Comprehensive Review of the Literature. Int. J. Environ. Res. Public Health 16, pii: E1709. https://doi.org/10.3390/ijerph16101709

Sollars PJ, Pickard GE. (2015) The Neurobiology of Circadian Rhythms. Psychiatr. Clin. North Am. 38, 645-665.

Spann SJ, Ottinger MA (2018) Longevity, Metabolic Disease, and Community Health. Prog. Mol. Biol. Transl. Sci. 155, 1-9.

Stenvers DJ, Scheer FAJL, Schrauwen P, la Fleur SE, Kalsbeek A. (2019) Circadian clocks and insulin resistance. Nat. Rev. Endocrinol. 15, 75-89. https://doi.org/10.1038/s41574-018-0122-1

Wu X, Chen L, Zeb F, Li C, Jiang P, Chen A, Xu C, Haq IU, Feng Q. (2019) Clock-Bmal1 mediates MMP9 induction in acrolein-promoted atherosclerosis associated with gut microbiota regulation. Environ. Pollut. 252, 1455-1463. https://doi.org/10.1016/i.envpol.2019.06.042

Wyatt SB, Winters KP, Dubbert PM. (2006) Overweight and obesity: prevalence, consequences, and causes of a growing public health problem. Am. J. Med. Sci. 331,166-74. https://doi.org/10.1007/s13679-015-0169-4

Yokoyama Y, Sasaki M, Sato K. (2019) Nutrition intake among the Japanese elderly: an intergenerational comparison based on National Health and Nutrition Survey scores. Ann. Hum. Biol., in press. https://doi.org/10.1080/03014460.2019.1662943

Youngstedt SD, Kripke DF, and Elliott JA. (2002) Circadian phase- delaying effects of bright light alone and combined with exercise in humans. Am. J. Physiol. Regul. Integr. Comp. Physiol. 282, R259R262. https://doi.org/10.1152/aipregu.00473.2001

Zwighaft Z, Aviram R, Shalev M, Rousso-Noori L, Kraut-Cohen J, Golik M, Brandis A, Reinke H, Aharoni A, Kahana C, Asher G. (2015) Circadian Clock Control by Polyamine Levels through a Mechanism that Declines with Age. Cell Metab. 22, 874-885. https://doi.org/10.1016/i.cmet.2015.09.011

\section{() $\odot \Theta \Theta$}

This work is licensed under a Attribution-NonCommercial-NoDerivatives 4.0 International (CC BY-NC-ND 4.0). 